\title{
Britain unveils four-year plans for postgraduate studies
}

London. Virtually all students aiming for a $\mathrm{PhD}$ will have to spend four rather than three years in postgraduate study to qualify for a research council grant, according to detailed proposals published by the British government last week. But the first year need not be a formal course, providing the material that would have been taught on such a course is covered in other ways.

The plans, prepared by the Office of Science and Technology (OST), put flesh on a proposal first made by the Advisory Board for the Research Councils and endorsed in last year's white paper (policy document) on science. Their aim is simultaneously to broaden the scope of postgraduate studies, to ensure their content is closer to the needs of potential employers and to provide a suitable exit point after a year for those who feel they are not cut out for research.

As in the white paper, the government aims to achieve these objectives by introducing a new master of research (MRes) qualification considered suitable both as an introduction to a full research training and - for those who choose not to take this route - as a valuable qualification in its own right for those entering other scientific careers.

But whereas the white paper suggested this qualification be awarded only to those who complete an initial one-year course, containing an introduction to issues such as the communication of science, as well as a basic training in research techniques, proposals are more flexible, allowing the MRes to be awarded to those completing the first year of a four-year $\mathrm{PhD}$ programme.

The new option is being seen by some as a response to pressure from some of the 'old' universities. These had claimed that they lack the resources to introduce a wide range of new postgraduate courses, and feared losing PhD students to other institutions if such courses became compulsory.

The OST proposals, which have been sent to a wide range of institutions for comment, also respond to pressure from university departments in subjects such as physics and engineering which are currently developing four-year undergraduate courses. They suggest that students completing such courses might be exempt from the MRes requirement.

They also suggest that students who have acquired equivalent training in other ways - for example through a period of employment in industry - might also be exempt from the full four-year $\mathrm{PhD}$.

OST officials argue that the new proposals are intended to move Britain away from the idea of seeing the $\mathrm{PhD}$ primarily as a research 'apprenticeship' and bring it more into line with other countries - in particular the United States - which require completion of a master's course before embarking on postgraduate research.

The additional flexibility has, in general, been welcomed by universities and other bodies that have acknowledged the benefits which the MRes scheme could bring, but had initially been concerned that excessively rigorous requirements (for example on the content on taught courses) could become counterproductive.

The new proposals are "certainly a move in the right direction", says Joe Vinen, professor of physics at the University of Birmingham and chairman of a committee set up by the Royal Society to report on the future of postgraduate education. His remarks are echoed by the Committee of Vice Chancellors and Principals. "The general feeling is hopeful, even though we still have some concerns about the flexibility of the MRes," says its spokesman, Ted Nields.

But several worries remain. A spokesman for the Association of British Pharmaceutical Industries - which had previously opposed the four-year $\mathrm{PhD}$ suggestion, arguing that the current arrangements are adequate to meet the industry's needs - says the organization is still unable to see the relevance of the MRes degree to the pharmaceutical industry.

Others are concerned at the career prospects for those holding an MRes. "It could be seen as a failed $\mathrm{PhD}$," says Colin Spedding, president of the Institute of Biology.

There is also a widespread worry that, in the absence of any additional funding from the government, the shift from three- to four-year postgraduate studies is likely to lead to a significant reduction in the number of $\mathrm{PhDs}$ produced by British universities, as well as a cut in the overall amount of research being carried out.

OST officials appear relatively unconcerned at this prospect. They argue on the one hand that a $\mathrm{PhD}$ may not always represent "value for money", either for the student concerned or for the government paying his or her costs; and, on the other, that it is "up to the research councils" to decide how to allocate their funding between support for research and postgraduate training.

But Paul Cottrell, assistant general secretary of the Association of University Teachers, says he does not accept that there is an argument for reducing the amount of public support given to $\mathrm{PhD}$ students. "This arbitrary decision to reduce numbers doesn't seem to have any basis, either market-led or otherwise," says Cottrell.

David Dickson and Fiona Gammie

\section{Dramatic growth forecast for UK biotechnology firms}

London. Britain's biotechnology sector is poised for dramatic growth, with a planned 44 per cent increase in staff and a 56 per cent rise in research and development (R\&D) spending over the next three years, according to a report released in London this week by accountants Arthur Andersen and the UK BioIndustry Association.

At the end of 1993, Britain had 166 startup companies in biotechnology, with a total turnover of some $£ 438$ million (US\$700 million) and R\&D spending of $£ 132$ million. By 1996, Arthur Andersen forecasts that turnover by existing companies will increase to $£ 878$ million, while R\&D spending will be $£ 206$ million.

Companies developing biotechnologyderived therapeutic agents will become the dominant force in the UK sector in this period. British biopharmaceutical companies at present have a total turnover of $£ 194$ million, and this is likely to rise to £319 million in 1996. At that time, they expect to be spending $£ 147$ million on $R \& D$ and employing more than 2,750 people.

The same trends are true across the board. As revenue among existing companies grows, so will the number of employees. The total workforce of the UK biotechnology sector at the end of 1993 was 7,400, and this is forecast to increase to 10,700 by 1996 .

These numbers are conservative, as they do not include any projections for companies likely to be formed between the autumn of 1993 and 1996. Arthur Andersen predicts an explosion of new start-ups over the next three years.

Recent changes to listing requirements of the London Stock Exchange for biopharmaceutical and diagnostic companies is expected to persuade venture capitalists that investment in biotechnology is now an attractive option, as they can receive a faster return on their investments when the companies sell shares on the public market.

Achieving the kind of growth forecast by Arthur Andersen will require assistance. British biotechnology companies will have to increase their links with the United States and, further down the line, with companies based in other European countries and in Japan.

"All segments of the UK biotechnology sector regard strategic alliances as being crucial to the realization of their commercial objectives," says Vernon Spender, the author of the report. "Over the next three years the geographic spread of alliances will shift increasingly towards the US and Japanese markets as UK biotechnology companies seek to access those markets and the research and regulatory skills of their domestic companies." 